\title{
Serum Bioactive Luteinizing and Follicle- Stimulating Hormone Concentrations in Girls Increase during Puberty ${ }^{1}$
}

\author{
JOSEPHINE Z. KASA-VUBU, VASANTHA PADMANABHAN, GAD B. KLETTER, \\ MORTON B. BROWN, EDWARD O. REITER, PIERRE C. SIZONENKO, AND INESE Z. BEITINS \\ Division of Pediatric Endocrinology, Department of Pediatrics and Communicable Diseases (J.Z.K.-V., V.P., \\ G.B.K., I.Z.B.] and Department of Biostatistics [M.B.B.] University of Michigan, Ann Arbor, Michigan 48109. \\ 0718; Department of Pediatrics, Baystate Medical Center, Tufts University School of Medicine, \\ Springfield, Massachusetts 01199 [E.O.R.]; and the Division of Biology of Growth and Reproduction. Department \\ of Pediatrics, University of Geneva, Geneva, Switzerland [P.C.Z.]
}

\begin{abstract}
FSH plays an essential role in folliculogenesis and ovarian growth. However, cross-sectional studies have not shown an increase in bioactive FSH (B-FSH) during puberty. To eliminate intersubject variability, we used a longitudinal design and tested the hypothesis that B-FSH increases during puberty. Thirty normal, healthy girls were enrolled in a longitudinal study from pubertal stages I to IV. The subjects were evaluated at 6-mo intervals; each visit consisted of pubertal staging, bone age determination by $x$-ray, measurements of serum immunoreactive FSH (I-FSH) and B-FSH $(n=14)$ or immunoreactive LH (I-LH) and bioactive LH $(B-L H)(n=18)$, and adrenal and ovarian steroids. All girls had clinical and hormonal characteristics of puberty. Both I-FSH and BFSH levels were relatively elevated before puberty, whereas serum I-LH and B-LH were low. From pubertal stages I to III, there was a modest yet significant rise in serum I-FSH $(p<0.001)$ and serum B-FSH $(p<0.01)$. Serum I-LH and B-LH concentrations showed the expected increases with puberty $(p<0.001)$, with serum BLH concentrations exhibiting a greater rise than I-LH $(p$ $<0.001$ ). Our results demonstrate that serum B-FSH and I-FSH increase during puberty. Relatively elevated B-FSH concentrations from early to midpuberty may be an important factor for ovarian growth while circulating $\mathrm{LH}$ and estrogen are still low. As puberty progresses, the continued and selective increase in $\mathrm{LH}$ induces a rise in estradiol and ultimately leads to ovulation. (Pediatr Res 34: 829-833, 1993)
\end{abstract}

\section{Abbreviations}

I-LH, immunoreactive luteinizing hormone B-LH, bioactive luteinizing hormone I-FSH, immunoreactive follicle-stimulating hormone B-FSH, bioactive follicle-stimulating hormone GnRH, gonadotropin-releasing hormone DHEA, dehydroepiandrosterone

Received March 24, 1992; accepted July 19, 1993.

Correspondence and reprint requests: Dr Josephine Z. Kasa-Vubu, D3252 Medical Professional Building, Division of Pediatric Endocrinology, Department of Pediatrics and Communicable Diseases. University of Michigan, Ann Arbor, M 48109-0718.

Supported by NIH Grant HD-18515 (I.Z.B.), NIH Training Grants 5 T32 DK 07245-14 and 5 T32-HD-07048 (J.Z.K.-V.), and the Swiss National Research Foundation Grants 3.0910.73 and 4.1090.73.

'Presented in part at the 27th Annual Meeting of the Society for Pediatric Research, Anaheim, CA, 1990.
DHEAS, dehydroepiandrosterone sulfate

$\Delta \mathbf{4 A}$, delta-4-androstenedione

$E_{2}$, estradiol

The prepubertal or inhibitory stage of sexual maturation is characterized by low serum gonadotropin levels (1). In contrast, the pubertal phase of sexual maturation is distinguished by a sleep-entrained increase in LH concentration (2). Animal studies have shown a strong correlation between GnRH secretory patterns and peripheral LH concentrations $(3,4)$. Derived from these animal models, the current neuroendocrine concepts of human puberty are based on the assumption that $\mathrm{LH}$ pulse frequency reflects GnRH secretory patterns (5). Such a strong correlation has not been demonstrated for FSH as measured by RIA (6). In light of the essential role of FSH in folliculogenesis and ovarian growth (7-9), this apparent lack of FSH increase during the puberty-related gonadal changes was unexpected.

The emerging concept of microheterogeneity of gonadotropins highlights the importance of qualitative changes of circulating hormones as an additional modulator of target site responses. In vitro bioassays for measurement of bioactive changes in gonadotropins $(10,11)$ have shown, as a general rule, that measurements obtained by in vitro bioassays were higher than those obtained by RIA. Several studies have conclusively demonstrated that B-LH concentrations during puberty follow changes in ILH concentrations but with a greater magnitude (12-14). In contrast, very little information is available regarding B-FSH secretory profiles during puberty. We have reported normative cross-sectional data on mean B-FSH levels through puberty $(6$, 15). Although B-LH is an established sensitive index of sexual maturation, B-FSH does not appear to be affected by the changes of the neuroendocrine milieu characteristic of puberty according to those cross-sectional studies.

Several important considerations have led us to the present study. First, the sample size in our cross-sectional study was small and therefore included significant intersubject variability. Second, Hassing et al. (16) have shown a sleep-entrained night time increase in B-FSH in early pubertal boys at a time when a nocturnal augmentation in LH secretion occurs (17). Third, an increase in urinary B-FSH excretion during puberty has been reported in three girls by Fauser et al. (18). In this study, we reduced intersubject variability with a longitudinal design and tested the hypothesis that qualitative changes in $\mathrm{FSH}$, reflected by $\mathrm{B}-\mathrm{FSH}$, occur during pubertal maturation in girls. 


\section{MATERIALS AND METHODS}

Subjects. Thirty normal, healthy girls for whom sufficient serum was available were enrolled from a larger longitudinal study conducted from 1971 through 1977 (19). In view of the longitudinal nature of the study, separate aliquots were stored at $-20^{\circ} \mathrm{C}$ until in vitro bioassay methodologies became available. They were followed prospectively at 6-mo intervals from a prepubertal stage until completion of sexual maturation. At each visit, they underwent a thorough physical examination including pubertal staging using a modification of Tanner's criteria (20), growth velocity based on the previous visit or the last $6 \mathrm{mo}$, and a wrist $x$-ray study documenting skeletal maturation using the standards of Greulich and Pyle (21). Blood samples were obtained for the determinations of serum concentrations of prolactin, DHEA, DHEAS, $\triangle 4 A$, and $E_{2}$ by RIA. The mean \pm SEM ages for pubertal stages I, II, III, IV, and V, were $9.1 \pm 0.2,10.7$ $\pm 0.1,11.5 \pm 0.1,12.0 \pm 0.2$, and $13.4 \pm 0.2 \mathrm{y}$, respectively. Because sufficient serum was not available for characterizing changes in both LH and FSH, subjects were randomly allocated to either an FSH or an LH group. Blood samples for both groups of girls were drawn in the morning between 0800 and $1100 \mathrm{~h}$. In the first group $(n=18)$, the serum samples were assayed for ILH by RIA and for B-LH by the rat interstitial cell testosterone production assay. In the second group $(n=14)$, the serum samples were assayed for I-FSH by RIA and B-FSH by the rat Sertoli cell aromatase induction assay. Two girls from whom sufficient serum was available had their blood samples analyzed for both $\mathrm{LH}$ and FSH and were therefore included in both groups.

$R I A$. Sera were kept frozen at $-20^{\circ} \mathrm{C}$ until assayed by RIA using previously described methods for prolactin (22), DHEA, DHEAS, and $\triangle 4 A(19,23,24)$; briefly, DHEA, and $\triangle 4 A$ were separated from the plasma using a celite chromatography system, and eluates were measured by RIA using a specific antibody. $E_{2}$ was purified and separated from estrone by celite chromatography (ethyl acetate-isooctane) (25) and assayed according to the method of Abraham (25). I-LH was measured using two standards (2nd IRP-hMG and LER 960). This latter precaution was taken to ensure that the microheterogeneity associated with a given LH standard would not affect the outcome of the measurements. The assay sensitivities were $1.0 \mathrm{IU} / \mathrm{L}$ and $0.1 \mathrm{ng} / \mathrm{mL}$, respectively, for the 2 nd IRP-hMG and LER 960 standards. The standard and antisera used for I-FSH were National Institute of Diabetes and Digestive and Kidney Diseases hFSH-3 and 510 (26), respectively. All samples for I-FSH were measured in one assay, and the assay sensitivity was $0.2 \mathrm{ng} / \mathrm{mL}$. Intraassay coefficients of variation for LH and FSH RIA were below $6 \%$ and $8 \%$, respectively.

In vitro bioassays. Separate aliquots of available sera that were stored frozen at $-20^{\circ} \mathrm{C}$ were assayed for bioactive gonadotropin concentrations, once the methodology became available. B-LH was measured by the production of testosterone by rat interstitial cells as previously validated by Dufau et al. (11). The sensitivity of the assay was $0.5 \mathrm{IU} / \mathrm{L}$ with 2 nd IRP-hMG standard and 0.2 $\mathrm{ng} / \mathrm{mL}$ for LER 960 . The intraassay and interassay coefficients of variation were less than $7 \%$ and $10 \%$, respectively, for the two standards.

B-FSH was measured by a rat Sertoli cell aromatase assay (10). The sensitivity of the assay was $1.0 \mathrm{ng} / \mathrm{mL}$ of $\mathrm{hFSH}-3$ and intraassay and interassay coefficients of variation were $13.2 \pm$ $2.7 \%$ (mean of five assays) and $16.1 \pm 1.5 \%$ (based on four quality controls and five assays), respectively.

Statistical analyses. The value of assay sensitivity was assigned to data with less than assay sensitivity. For each subject, the mean of all values within each pubertal stage was calculated. To adjust for heterogeneity of variance, I-LH, B-LH, I-FSH, and BFSH values were logarithmically transformed. An $F$ test of the equivalence of the stages was tested by fitting a general linear model to the data and adjusting for subject to subject differences; this model uses all information available from each individual even when the individual does not have data for all stages. In addition, for the six subjects who had data in stages I through IV, a repeated-measures analysis of variance was performed to compare stages. The trend of these results was similar to that obtained by the use of the general linear model and is not presented.

\section{RESULTS}

Clinical and hormonal characteristics. Table 1 summarizes the clinical characteristics (height, weight, bone age, and growth velocity) and serum concentrations of adrenal steroids (DHEA, DHEAS, and $\triangle 4 A$ ), prolactin, and $E_{2}$ in all subjects. From pubertal stages I through $\mathrm{V}$, there were significant progressive increases in bone age, height, mean growth velocity, and serum concentrations of prolactin and adrenal and ovarian steroids $(p<0.001)$. The mean age of menarche was $13 \mathrm{y} \pm 2$ mo.

Mean immunoreactive and bioactive gonadotropins. Progressive changes in mean serum gonadotropin and $E_{2}$ concentrations during puberty for both the $\mathrm{LH}$ and $\mathrm{FSH}$ groups are displayed in Table 2 and Figure 1. Serum B-LH concentrations as measured by both 2 nd IRP and LER 960 standards showed progressive increases with pubertal stages $(p<0.0001)$ (Table 2$)$. Similarly, I-LH concentrations as measured by both standards also exhibited progressive increases $(p<0.0001)$. The changes in B-LH concentrations were larger than those in I-LH concentrations. The difference between $\mathrm{B}-\mathrm{LH}$ and $\mathrm{I}-\mathrm{LH}$ concentrations became more pronounced as puberty progressed (Fig. 1, panel $A$ ). The B-LH/I-LH ratio showed a significant increase with the progression of puberty $(p<0.0001)$. Serum $E_{2}$ showed the expected gradual pubertal increase throughout sexual maturation (Fig. 1, panel $A$ ).

The changes in serum B-FSH and I-FSH concentrations and $\mathrm{E}_{2}$ concentrations for the 14 girls in the FSH-only group are summarized in Table 2 and Figure $1 B$. Mean serum I-FSH concentrations showed a significant increase $(p<0.0001)$ from pubertal stages I to III; thereafter, the serum concentrations plateaued. Similarly, serum B-FSH levels rose from pubertal stages I to III $(p<0.01)$; thereafter, it seems from the small number of subjects, that serum B-FSH concentrations plateaued. The B-FSH/I-FSH ratio averaged $1.4 \pm 0.2,1.1 \pm 0.1,1.0 \pm 0.1$, $0.8 \pm 0.1$, and $1.2 \pm 0.2$ for the five pubertal stages and decreased from pubertal stages I through IV $(p<0.01)$. As seen in the LH group, serum $E_{2}$ concentrations exhibited the expected steady increase characteristic of puberty.

\section{DISCUSSION}

The results demonstrate that despite the relatively elevated levels of serum I-FSH and B-FSH in prepubertal girls, serum BFSH and I-FSH concentrations increase during early pubertal stages. Differential regulation of B-FSH and B-LH becomes evident as puberty progresses: B-LH and $E_{2}$ secretion increase markedly, whereas B-FSH levels stabilize and reach a plateau. These results contrast with our earlier results from a crosssectional study of boys and girls in which serum B-FSH concentration remained constant throughout puberty (15). The longitudinal component of the present study reduced intersubject variability, thus unmasking modest but significant increases in serum B-FSH concentration. It is possible that a longitudinal experimental design incorporating overnight frequent sampling may show more pronounced changes in the pattern of B-FSH secretion. The single daily sampling performed in this study did not allow for the assessment of gonadotropin pulsatility, nor was it possible to determine whether sleep-entrained changes occurred. A sleep-entrained nighttime rise of B-FSH was previously demonstrated in early pubertal boys (16), and girls with precocious puberty have increased excretion of urinary B-FSH (18).

As expected, the B-LH signal increased more than I-LH, and as a consequence the B-LH/I-LH ratio increased with progression 
BIOACTIVE LH AND FSH IN GIRLS

Table 1. Clinical characteristics and hormone concentrations expressed as mean \pm SEM from pubertal stages $P I$ through $P V$, after F test analysis throughout pubertal stages*

\begin{tabular}{|c|c|c|c|c|c|c|}
\hline & \multicolumn{5}{|c|}{ Pubertal stage } & \multirow[b]{2}{*}{$p$ value } \\
\hline & I & II & III & IV & $\mathrm{V}$ & \\
\hline Age $(y)$ & $9.1 \pm 0.2$ & $10.7 \pm 0.2$ & $11.5 \pm 0.1$ & $12.0 \pm 0.2$ & $13.4 \pm 0.2$ & $<0.0001$ \\
\hline Height $(\mathrm{cm})$ & $136.9 \pm 1.4$ & $145.3 \pm 1.1$ & $152.2 \pm 0.9$ & $157.0 \pm 1.2$ & $160.2 \pm 1.4$ & $<0.0001$ \\
\hline Weight (kg) & $30.8 \pm 1.5$ & $35.7 \pm 1.4$ & $40.8 \pm 1.6$ & $43.6 \pm 1.3$ & $50.3 \pm 2.3$ & $<0.0001$ \\
\hline Bone age $(y)$ & $9.1 \pm 0.2$ & $10.8 \pm 0.1$ & $12.0 \pm 0.1$ & $12.8 \pm 0.1$ & $14.2 \pm 0.2$ & $<0.0001$ \\
\hline $\mathrm{GV}(\mathrm{cm} / 6 \mathrm{mo})$ & $2.6 \pm 0.1$ & $3.1 \pm 0.1$ & $3.5 \pm 0.8$ & $3.6 \pm 0.2$ & $2.5 \pm 0.2$ & $<0.0001$ \\
\hline Prolactin $(\mu \mathrm{g} / \mathrm{L})$ & $5.6 \pm 0.4$ & $6.2 \pm 0.5$ & $7.0 \pm 0.6$ & $7.7 \pm 1.0$ & $9.0 \pm 0.6$ & $<0.01$ \\
\hline$n$ & 24 & 30 & 24 & 15 & 21 & \\
\hline DHEA $(\mathrm{nmol} / \mathrm{L})$ & $3.5 \pm 0.3$ & $8.0 \pm 1.0$ & $11.2 \pm 1.7$ & $10.5 \pm 1.7$ & $12.2 \pm 1.7$ & $<0.0001$ \\
\hline$\Delta 4 \mathrm{~A}(\mathrm{nmol} / \mathrm{L})$ & $0.7 \pm 0.0$ & $1.4 \pm 0.3$ & $2.3 \pm 0.3$ & $3.4 \pm 0.7$ & $3.1 \pm 0.3$ & $<0.0001$ \\
\hline$n$ & 15 & 17 & 13 & 6 & 9 & \\
\hline DHEAS $(\mu \mathrm{mol} / \mathrm{L})$ & $0.5 \pm 0.1$ & $1.0 \pm 0.2$ & $0.9 \pm 0.1$ & $1.5 \pm 0.3$ & $1.4 \pm 0.2$ & $<0.0001$ \\
\hline$n$ & 17 & 19 & 15 & 8 & 10 & \\
\hline
\end{tabular}

* GV, growth velocity. Mean age of menarche was $13 \pm 2$ mo.

Table 2. Serum LH and FSH concentrations expressed as mean \pm SEM from pubertal stages I through $V$ after analysis by $F$ test throughout pubertal stages

\begin{tabular}{|c|c|c|c|c|c|c|}
\hline & \multicolumn{5}{|c|}{ Pubertal stage } & \multirow[b]{2}{*}{$p$ value } \\
\hline & $\mathrm{I}$ & II & III & IV & V & \\
\hline $\mathrm{I}-\mathrm{LH}^{*}(\mathrm{mIU} / \mathrm{mL})$ & $1.1 \pm 0.1$ & $1.7 \pm 0.2$ & $2.5 \pm 0.3$ & $4.9 \pm 0.6$ & $7.7 \pm 1.0$ & $<0.001$ \\
\hline $\mathrm{I}-\mathrm{LH}+(\mathrm{ng} / \mathrm{mL})$ & $0.8 \pm 0.2$ & $1.1 \pm 0.3$ & $2.4 \pm 0.5$ & $8.5 \pm 1.7$ & $12.1 \pm 1.6$ & $<0.001$ \\
\hline B-LH $(\mathrm{ng} / \mathrm{mL})$ & $1.3 \pm 0.5$ & $2.0 \pm 0.4$ & $6.6 \pm 1.3$ & $17.5 \pm 2.1$ & $29.1 \pm 4.0$ & $<0.001$ \\
\hline$n$ & 12 & 18 & 13 & 10 & 14 & \\
\hline I-FSH (ng/mL) & $2.0 \pm 0.2$ & $2.5 \pm 0.2$ & $3.7 \pm 0.4$ & $3.3 \pm 0.2$ & $3.6 \pm 0.4$ & $<0.001$ \\
\hline B-FSH $(\mathrm{ng} / \mathrm{mL})$ & $2.6 \pm 0.4$ & $2.8 \pm 0.4$ & $3.7 \pm 0.8$ & $2.8 \pm 0.7$ & $3.9 \pm 0.6$ & $<0.01$ \\
\hline$n$ & 13 & 14 & 12 & 6 & 9 & \\
\hline
\end{tabular}

* LH standard = 2nd IRP hMG.

† LH standard = LER 960.

of puberty $(12-14,27)$. In contrast, the B-FSH signal showed only a modest rise through pubertal stage III, but as a result the B-FSH/I-FSH ratio decreased through pubertal stage IV. The secretory patterns of B-FSH and its isoform distribution during puberty need further investigation. The divergence of the gonadotropin bioactive/immunoreactive ratios (increased $\mathrm{LH}$ versus decreased FSH) provides additional support for the differential regulation of $\mathrm{LH}$ and $\mathrm{FSH}$.

The differences in magnitude of B-FSH and I-FSH increases could result from several possible sources. First, there could be a change in the quality of the FSH secreted by the pituitary gland. Several observations support the hypothesis that GnRH and/or estrogens modulate FSH bioactivity or create a shift of FSH isoform distribution toward the relatively more basic forms. For example, Wide et al. (28) showed qualitative changes in the FSH secreted in response to GnRH stimulation in girls with Turner's syndrome; the newly secreted isoforms had a less negative median charge. In the intact female lamb, experimentally induced puberty induces an increase in circulating B-FSH, which also correlates with a shift in circulating isoform distribution toward a relatively more basic $\mathrm{pI}$ (29). Relatively more basic isoforms have greater in vitro bioactivity (30). Finally, estrogen treatment of postmenopausal women was associated with a shift in the excretion of FSH toward a relatively more basic and biopotent isoform mix (6). It will be important to determine in future studies whether the changes in B-FSH observed in this study reflect shifts in FSH isoform distribution throughout puberty in girls.

A second mechanism by which B-FSH secretion would be selectively altered could be mediated by growth factors. Indeed, gonadal growth factors such as IGF-I, transforming growth factor, and epidermal growth factor may have a modulatory role in the mediation of FSH action (7). At the gonadal level, nonspecific effects of serum growth factors may contribute to the observed discrepancies between I-FSH as measured by RIA and B-FSH as measured by the Sertoli cell aromatase assay (one of several biologic end measures of FSH action in the Sertoli cells). Adashi et al. (31) found IGF-I to be a powerful potentiator of the actions of FSH in rat granulosa cells. It has been well documented that IGF-I increases dramatically during puberty (32), a time also characterized by peak growth velocities. Although IGF-I levels were not measured in this particular study, our subjects did show the progressive clinical and hormonal changes characteristic of sexual maturation, notably the significant increase in growth velocity. Therefore, puberty-associated changes in circulating levels of IGF-I could theoretically interfere with our FSH bioassay measurements. However, in the in vitro B-FSH system, because insulin is added to the medium, further addition of IGFI to the Sertoli cell cultures does not alter the levels of FSHinduced aromatase (33).

Because we are measuring $E_{2}$ as an end point of FSH action, circulating levels of $E_{2}$ could contribute to the final B-FSH measurement (34). However, in the pubertal samples used in the present study, circulating levels of $E_{2}$ ranged from 20 to $100 \mathrm{pg} / \mathrm{mL}$. Because we are using $10 \mu \mathrm{L}$ of serum in the bioassay, the absolute amount of $E_{2}$ added ranges from 0.2 to $1.0 \mathrm{pg}$ and has no effect on the final measurement of serum B-FSH concentrations. Furthermore, in the luteal phase of the menstrual cycle, $E_{2}$ levels are high, yet B-FSH levels are low (30). Considering the longitudinal nature of the study, prolonged storage may have deleterious effects on the bioactive gonadotropin isoforms. However, quality control serum pools from both male and female subjects measured in the FSH bioassay over the last 4-y period (1989-1992) showed no evidence of deterioration of B-FSH with long-term storage. 
Panel A

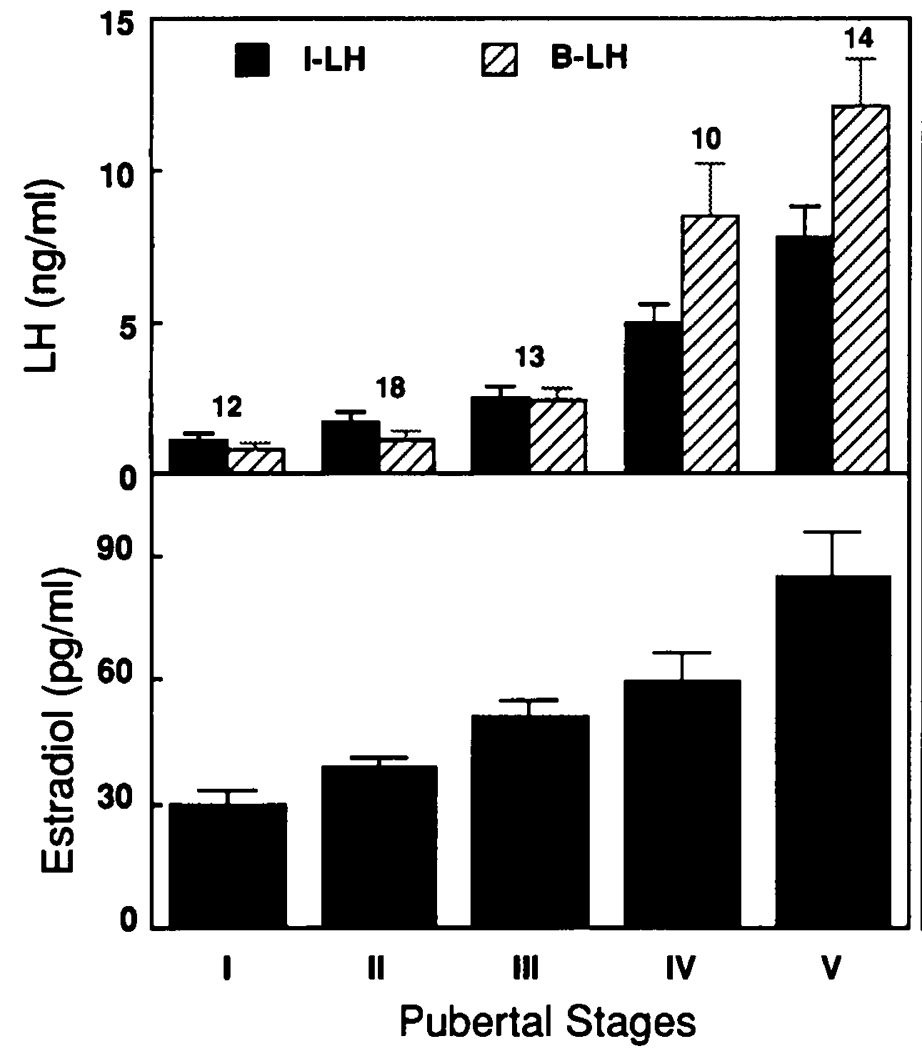

Panel $B$

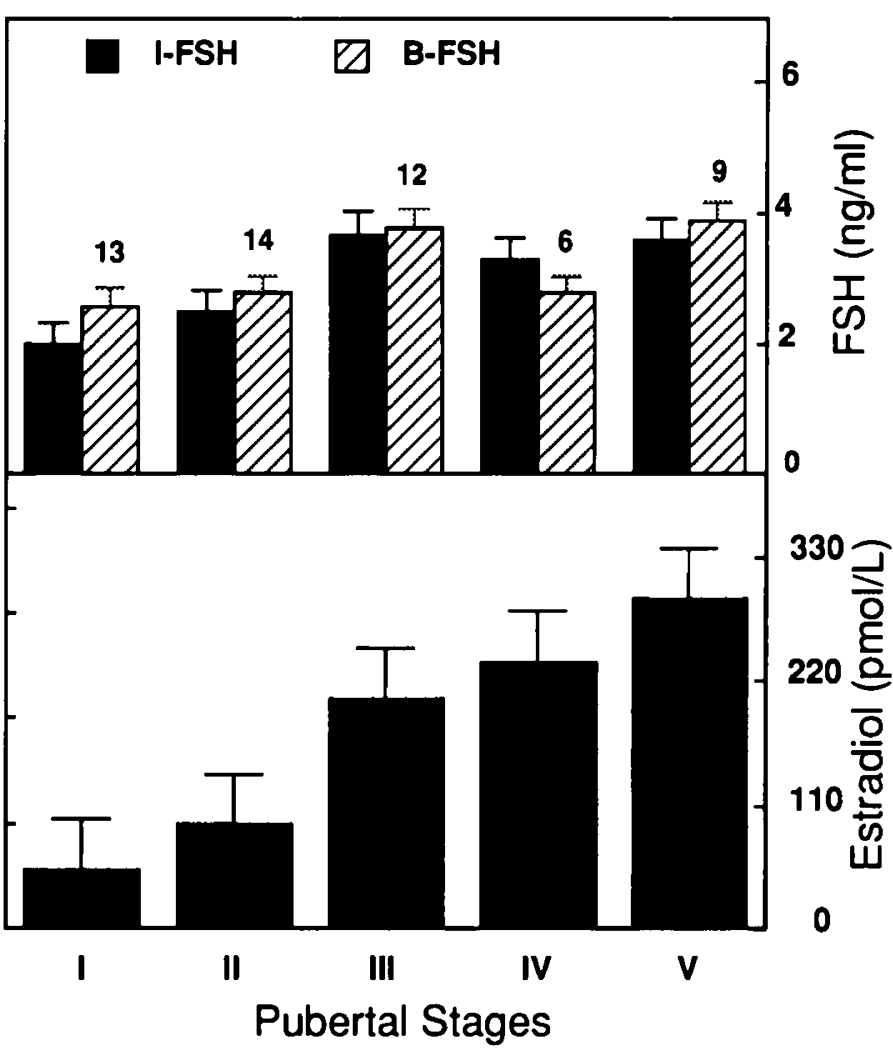

Fig. 1. Panel A, Mean B-LH, I-LH using the LER 960 standard, and $\mathrm{E}_{2}$ concentrations relative to pubertal stages I through V. Panel B, Mean BFSH, I-FSH, and $E_{2}$ concentrations relative to pubertal stages I through V. The numbers above the bars in the top graphs represent the number of subjects at each pubertal stage.

It appears that FSH has a trophic role in the ovary in the absence of pubertal $\mathrm{LH}$ and $\mathrm{E}_{2}$ secretion. Ovarian size increases steadily and limited ovarian follicular growth occurs during the prepubertal years when the reproductive axis is in a relatively quiescent state (35). Unsustained sexual precocity such as breast budding is not uncommon in girls (36). Furthermore, it appears that recombinant FSH alone can induce growth of preovulatory follicles in the absence of optimal $E_{2}$ concentrations. After such treatment, Shoot et al. (37) observed that intrafollicular $\Delta 4 \mathrm{~A}$ was low in a woman with hypogonadotrophic hypogonadism. These findings would indicate that follicular growth and steroidogenic activity are differentially regulated in granulosa cells.

All subjects in our study showed the expected clinical and hormonal changes of puberty: increase in growth velocity and advancement of skeletal maturation, as well as increased production of gonadal and adrenal steroids. The patterns of serum BFSH secretion in our subjects are in keeping with earlier results from studies in normal women and patients with gonadal dysgenesis in whom rising peripheral concentrations of either endogenous or exogenous $E_{2}$ led to a nonparallel rise in both IFSH and B-FSH (30). Some of our physically immature subjects had $E_{2}$ values compatible with an early pubertal range, and it is possible that these pubertal stage I subjects on the verge of puberty blunted the magnitude of B-FSH increase in comparison with latter maturational stages.

In conclusion, the results of this study highlight the complexity of the regulation of FSH secretion and its role in the maturing ovary. These regulatory mechanisms are still poorly understood but undoubtedly play an indispensable role in the maintenance and development of ovarian follicles.

Acknowledgments. The authors thank Joanne Sonstein and T. Ostrea for their technical assistance; C. Schoepfer for nursing assistance during the longitudinal study; and the Center for the Studies of Reproduction for the use of the following services: The Standards and Reagents Core Facility for RIA reagents, the Small Animal Core Facility for rats used in the bioassays, and the Data Analysis Core for assistance with data analysis. We also thank the National Hormone and Pituitary Program for supplying assay reagents.

\section{REFERENCES}

1. Sizonenko P 1987 Normal sexual maturation. Pediatrician 14:191-201

2. Boyar RM, Wu RHK, Roffwarg H, Kapen S, Weitzman ED, Hellman L Finkelstein JW 1976 Human puberty: 24-hour estradiol patterns in pubertal girls. J Clin Endocrinol Metab 43:1418-1421

3. Clarke IJ, Cummins JT 1982 The temporal relationship between gonadotropin releasing hormone (GnRH) and luteinizing hormone (LH) secretion in ovariectomized ewes. Endocrinology 111:1737-1739

4. Moenter SM, Caraty A, Karsch FJ 1990 The estradiol-induced surge of gonadotropin-releasing hormone in the ewe. Endocrinology 127:1375-1384

5. Marshall JC, Kelch RP 1986 Gonadotropin-releasing hormone: role of pulsatile secretion in the regulation of reproduction. N Engl J Med 315:1459-1468

6. Beitins IZ, Padmanabhan V 1991 Bioactivity of gonadotropins. Endocrinol Metab Clin North Am 20:85-120

7. Hsueh AJW, Bicsak TA, Jia Y-C, Dahl KD, Fauser BCJM, Galway AB, Czeka N, Pavlou SN, Papkoff H, Keene J, Boime I 1989 Granulosa cells as hormone targets: the role of biologically active follicle-stimulating hormone in reproduction. Recent Prog Horm Res 45:209-277

8. Greenwald GS, Terranova PF 1988 Follicular selection and its control. In: Knobil E, Neill J (eds) The Physiology of Reproduction. Raven Press, New York, pp 387-445

9. Richards JS 1979 Hormonal control of ovarian follicular development: a 1978 perspective. Recent Prog Horm Res 35:343-373

10. Padmanabhan V, Chappel SC, Beitins IZ 1988 An improved in vitro bioassay for follicle-stimulating hormone: suitable for measurement in unextracted human serum. Endocrinology 121:1089-1098

11. Dufau ML, Pock R, Neubauer A, Catt KS 1976 In-vitro bioassay of LH in human serum: the rat interstitial cell testosterone (RICT) assay. J Clin Endocrinol Metab 42:958-969 
12. Lucky AW, Rich BH, Rosenfield RL, Fang VS, Roche-Bender N 1980 LH bioactivity increases more than immunoreactivity during puberty. J Pediatr 97:205-213

13. Reiter EO, Sizonenko PC, Witt MF, Beitins IZ 1984 Sex differences in the detectability of bio (B) and immuno (I)-LH in early pubertal development: a longitudinal study. Pediatr Res 18:175A(abstr)

14. Reiter EO, Biggs DE, Veldhuis JD, Beitins IZ 1984 Pulsatile release of bioactive luteinizing hormone in prepubertal girls: discordance with immunoreactive luteinizing pulses. Pediatr Res 21:409-413

15. Beitins IZ, Padmanabhan V, Kasa-Vubu J, Kletter GB, Sizonenko PC 1990 Serum bioactive follicle-stimulating hormone concentrations from prepuberty to adulthood: a cross-sectional study. J Clin Endocrinol Metab 71:10221027

16. Hassing JM, Padmanabhan V, Kelch RP, Brown MB, Olton PR, Sonstein JS, Foster CM, Beitins IZ 1990 Differential regulation of serum I-LH and BFSH by testosterone in early pubertal boys. J Clin Endocrinol Metab 70:1082-1089

17. Haie PM, Khoury S, Foster CM, Beitins IZ, Hopwood NJ, Marshall JC, Kelch RP 1988 Increased luteinizing hormone pulse frequency during sleep in early to mid-pubertal boys. J Clin Endocrinol Metab 66:785-791

18. Fauser BCJM, Soto D, Czekala NM, Hsueh AJW 1989 Granulosa cell aromatase bioassay: changes of bioactive FSH levels in the female. J Steroid Biochem 33:721-726

19. Sizonenko PC, Paunier L 1975 Hormonal changes in puberty. IIl Correlation of plasma dehydroepiandrosterone, testosterone, FSH and LH with stages of puberty and bone age in normal boys and girls in patients with Addison's disease or hypogonadism or with premature or late adrenarche. J Clin Endocrinol Metab 41:894-904

20. Sizonenko PC, Burr IM, Kaplan SL, Grumbach MM 1970 Hormonal changes in puberty. II. Correlation of serum luteinizing hormone and follicle-stimulating hormone with stages of puberty and bone age in normal girls. Pediatr Res 4:36-45

21. Greulich WW, Pyle SI 1959 Radiographic Atlas of Skeletal Development of the Hand and Wrist, 2nd Ed. Stanford University Press, Stanford, CA

22. Aubert ML, Sizonenko PC, Kaplan SL, Grumbach MM 1977 The ontogenesis of human prolactin from fetal life to puberty. In: Crosignani PG, Robyn C (eds) Prolactin and Human Reproduction. Academic Press, London, pp 9-20

23. Sizonenko PC, Paunier L, Carmignac D 1976 Hormonal changes during puberty. IV. Longitudinal study of adrenal secretions. Horm Res 7:288-302

24. Abraham CE, Malimos F, Carza R 1977 Radioimmunoassay of steroids. In: Abraham GE (ed) Handbook of Radioimmunoassay. Marcel Decker, New York, pp 591-656
25. Abraham G 1976 Radioimmunoassay of oestradiol-17 $\beta$ in plasma. In: Breuer $\mathrm{H}$, Krüskemper $\mathrm{H}$ (eds) Methods of Hormone Analysis. John Wiley and Sons, New York, pp 108-115

26. Midgley AR 1967 Radioimmunoassay for human follicle-stimulating hormone. J Clin Endocrinol Metab 27:295-299

27. Lucky AW, Rich BH, Rosenfield RL, Fang VS, Roche-Bender N 1980 Bioactive LH: a test to discriminate true precocious puberty from premature thelarche and adrenarche. J Pediatrics 97:214-216

28. Wide L, Albertsson-Wikland K 1990 Change in electrophoretic mobility of human follicle-stimulating hormone in serum after administration of gonadotropin releasing hormone. J Clin Endocrinol Metab 70:271-276

29. Padmanabhan V, Mieher CD, Borondy M, I'Anson H, Wood RI, Landefeld TD, Foster DL, Beitins IZ 1992 Circulating bioactive FSH and less acidic FSH isoforms increase during experimental induction of puberty in the female lamb. Endocrinology 131:213-220

30. Padmanabhan V, Lang LL, Sonstein J, Kelch RP, Beitins IZ 1988 Modulation of serum follicle-stimulating hormone bioactivity and isoform distribution by estrogenic steroids in normal women and in gonadal dysgenesis. J Clin Endocrinol Metab 67:465-473

31. Adashi EY, Resnick CE, D'Ercole AJ, Svoboda ME, Van Wyk JJ 1985 Insulinlike growth factors as intraovarian regulators of granulosa cell growth and function. Endocr Rev 6:400-420

32. Luna AM, Wison DM, Wibbelsman CJ, Brown RC, Nagashima RJ, Hintz RL, Rosenfeld RG 1983 Somatomedins in adolescence: a cross-sectional study of the effect of puberty on plasma insulin-like growth factor I and II levels. J Clin Endocrinol Metab 57:268-271

33. Padmanabhan V, Sonstein J, Olton PL, Nippoldt T, Menon KMJ, Marshall JC, Kelch RP, Beitins IZ 1988 Serum bioactive follicle-stimulating hormonelike activity increases during pregnancy. J Clin Endocrinol Metab 69:968977

34. Simoni M, Khan SA, Nieschlag E 1991 Serum bioactive follicle-stimulatinglike activity in human serum in human pregnancy is a methodological artifact. J Clin Endocrinol Metab 73:1118-1122

35. Ross GT 1985 Disorders of the ovary and the female reproductive tract. In: Williams (ed) Endocrinology Textbook. WB Saunders, Philadelphia, pp 206-258

36. Kaplan SL and Grumbach MM 1990 Clinical review 14: pathophysiology and treatment of sexual precocity. J Clin Endocrinol Metab 71:785-789

37. Shoot DC, Herlan JT, Bennink C, Mannaerts BMJL Lamberts SWJ, Bouchard P, Fauser BCJM 1992 Human recombinant follicle-stimulating hormone induces growth of preovulatory follicles without concomitant increase in androgen and estrogen biosynthesis in a woman with isolated gonadotropin deficiency. J Clin Endocrinol Metab 74:1471-1473 